\title{
Article \\ Polarization Splitter-Rotator Based on Multimode Waveguide Grating
}

\author{
Yannong Luo ${ }^{1}$, Renyou Ge ${ }^{2}$, Haozhi Luo ${ }^{2}$, Meiyan $\mathrm{Wu}^{3}$, Lidan Zhou ${ }^{2}$, Makunda Aryal ${ }^{4}$, Wenwei Li ${ }^{1}$, \\ Jianhui Yuan ${ }^{3}$, Jian $\mathrm{Xu}^{5}$, Quanxue Lan ${ }^{6}$, Yongqing $\mathrm{Li}^{4}$ and Xinlun Cai ${ }^{2, *}$ \\ 1 Laboratory of Biomedical Photonics \& Engineering, Life Science Institute, Guangxi Medical University, \\ Nanning 530021, China; luoyannong@gxmu.edu.cn (Y.L.); liwenwei@gxmu.edu.cn (W.L.) \\ 2 State Key Laboratory of Optoelectronic Materials and Technologies, School of Electronics and Information \\ Technology, Sun Yat-Sen University, Guangzhou 510275, China; gery@mail2.sysu.edu.cn (R.G.); \\ luohzh3@mail2.sysu.edu.cn (H.L.); zhould@mail2.sysu.edu.cn (L.Z.) \\ 3 Laboratory of Biomedical Photonics \& Engineering, School of Basic Medical Sciences, Guangxi Medical \\ University, Nanning 530021, China; wumeiyan@stu.gxmu.edu.cn (M.W.); jianhui831110@gxmu.edu.cn (J.Y.) \\ 4 Department of Physics, East Carolina University, Greenville, NC 27858-4353, USA; \\ aryalm18@students.ecu.edu (M.A.); liy@ecu.edu (Y.L.) \\ 5 School of Economics and Commerce, South China University of Technology, Guangzhou 510640, China; \\ jianxu@scut.edu.cn \\ 6 Longgang Center for Disease Control and Prevention, Shenzhen 518172, China; lanquanxue@126.com \\ * Correspondence: caixlun5@mail.sysu.edu.cn
}

check for updates

Citation: Luo, Y.; Ge, R.; Luo, H.; Wu, M.; Zhou, L.; Aryal, M.; Li, W.; Yuan, J.; Xu, J.; Lan, Q.; et al. Polarization Splitter-Rotator Based on Multimode Waveguide Grating. Crystals 2021, 11, 1170. https://doi.org/10.3390/ cryst11101170

Academic Editors: John Rarity, Tullio Scopigno, Mike Taverne and Ying-Lung Daniel Ho

Received: 7 September 2021

Accepted: 24 September 2021

Published: 26 September 2021

Publisher's Note: MDPI stays neutral with regard to jurisdictional claims in published maps and institutional affiliations.

Copyright: (c) 2021 by the authors. Licensee MDPI, Basel, Switzerland. This article is an open access article distributed under the terms and conditions of the Creative Commons Attribution (CC BY) license (https:// creativecommons.org/licenses/by/ $4.0 /)$.

\begin{abstract}
We demonstrate a polarization splitter rotator (PSR) based on multimode waveguide grating (MWG) on a silicon-on-insulator (SOI) platform. Bloch mode hybridization in mini-stopband is exploited to achieve high polarization conversion efficiency. The fabricated device yields a high extinction ratio of $>53 \mathrm{~dB}$ and $>31 \mathrm{~dB}$, low crosstalk of $<-26.4 \mathrm{~dB}$ and $<-40 \mathrm{~dB}$ for the injected $\mathrm{TE}_{0}$ and $\mathrm{TM}_{0}$ mode, with average insertion loss of $1.2 \mathrm{~dB}$ and $1.5 \mathrm{~dB}$ in the wavelength regime $1552 \mathrm{~nm}-$ $1562 \mathrm{~nm}$. Such a device shows great design flexibility and an easy fabrication process, serving as a good candidate in integrated polarization diversity circuits, especially for applications requiring spectra manipulation. Additionally, the polarization conversion approach provides opportunities to develop novel polarization management devices.
\end{abstract}

Keywords: polarization splitter rotator; multimode waveguide grating; silicon photonics

\section{Introduction}

Silicon-on-insulator (SOI) has become one of the most promising platforms for photonic integration benefiting from its low cost, high-density integration, and compatibility with CMOS fabrication processes. However, the high index contrast introduces significant polarization dependence, which makes silicon photonic devices incompatible with fiber communication applications where the polarization state in optical fiber is typically random. One efficient solution to eliminate the polarization sensitivity is to use a polarization splitter-rotator (PSR) [1-5], in which the $\mathrm{TE}_{0}$ mode and $\mathrm{TM}_{0}$ mode can be separated into two individual waveguides. Meanwhile, one of the polarization states will be converted to the orthogonal one, normally chosen as $\mathrm{TE}_{0}$ mode considering that most devices are optimized only for $\mathrm{TE}_{0}$ polarization. Such a polarization handling device is also desired on other material platforms, and has been demonstrated on platforms including InP [6,7], SiN [8] and lithium-niobate-on-insulator (LNOI) $[9,10]$. Vertical asymmetrical structures are normally required to implement polarization conversion schemes including covering different cladding material [1], fabricating a bi-level taper [11,12], or introducing additional top structures such as gold [13] and SiN [14]. The operation principle of PSRs can be classified into two categories of mode coupling [15] and mode evolution [16,17], according to the energy exchange path when polarization rotation. For mode coupling based PSRs, 
phase-matching condition should be satisfied. The typical structures adopted are asymmetrical directional coupler (ADC) [18], tapered DC [19], bend DC [20,21], and so on. For mode evolution ones, mode hybridization between $\mathrm{TM}_{0}$ mode and forward $\mathrm{TE}_{1}$ mode can occur when light propagates along the adiabatic taper or multimode waveguide [22]. It should be noted that all the reported PSRs are designed for broadband operation, aiming as universal schemes for realizing polarization-transparent photonic integrated circuits (PICs). However, for some critical applications such as polarization insensitive wavelength division (de)multiplexer $[23,24]$, wavelength selective devices such as arrayed waveguide gratings (AWGs) are subsequently required to implement wavelength multiplexing [25], inevitably incurring extra insertion loss and footprint and design complexity to the whole on-chip system. Exploiting novel polarization conversion mechanisms and developing new functional devices are desirable for PICs application.

Mini-stopband (MSB) is derived from the anti-crossing between Bloch modes [26,27]. There have been numerous interesting applications based on MSB, mostly in two dimensional photonic crystal (2D-PhC) such as pulse compression [28], coarse wavelength selection [29], optical filters [30], and selective mirroring in PhC lasers [31,32]. Several functional components based on MSB have also been demonstrated including polarization beam splitter [33] and tunable optical band stop filters [34], in one dimensional photonic crystal (1D-PhC). However, the authors have never considered in particular the coupling between Bloch modes with different polarization, and resultant polarization conversion in multimode waveguide grating (MWG).

In this paper, we demonstrate a novel MWG-based PSR. An anti-crossing of Bloch modes in MSB is exploited to archive highly efficient polarization rotation. The proposed PSR boasts a high extinction ratio, low crosstalk, an easy fabrication process, and great design flexibility. Additionally, such a device can be further cascaded with grating assisted contra-directional couplers (contra-DCs) [35,36], paving the way for critical applications such as polarization insensitive wavelength division (de)multiplexer $[23,24]$ and multichannel polarization-multiplexed differential quadrature phase-shift keying (PM-DQPSK) transceiver [37,38].

\section{Device Structure and Working Principle}

The proposed PSR is schematically illustrated in Figure 1, and consists of a linearly tapered multimode waveguide grating (MWG) and adiabatic coupler (AC). The silicon strip waveguides are $220 \mathrm{~nm}$ high sitting on a $2 \mu \mathrm{m}$ buried oxide layer with air cladding, for the demand of vertical symmetry breaking. For the injected $\mathrm{TE}_{0}$ mode, the light beam keeps propagating along $A C, M W G$, and linearly tapered waveguide (length $L_{2}$ ), then exits at the through (TRU) port. In the case of $\mathrm{TM}_{0}$ input, the mode is first preserved in the $A C$ region (length $L_{1}$, Gap G), then reversely coupled to be the $T_{1}$ mode by MWG due to the satisfied phase-matching condition and Bloch mode hybridization. In the AC section, the backward $\mathrm{TE}_{1}$ mode finally evolves into a $\mathrm{TE}_{0}$ mode of the isolated bottom taper waveguide (width from $\mathrm{W}_{4}$ to $\mathrm{W}_{3}$ ) and bends away to the cross (CRO) port.

The structure parameters of width, period, grating number, and corrugation width in the uniform MWG region are denoted by $\mathrm{W}_{2}, \Lambda, \mathrm{N}$, and $\delta \mathrm{w}$, respectively, as labeled in Figure $1 \mathrm{~b}$. As a potential application scenario, we also propose an easy architecture of a polarization insensitive wavelength duplexer, simply by cascading MWG-based PSR and grating assisted contra-directional coupler. As depicted in Figure 1c, the injected $\mathrm{TM}_{0}$ mode will be backward converted to $\mathrm{TE}_{0}$ by PSR and dropped at different ports because of the different grating period $\Lambda$. Meanwhile, the injected $\mathrm{TE}_{0}$ mode propagates through the whole PSRs region, is then dropped to different ports by contra-DCs. Note that the longitudinal-apodization design is normally requires suppressing the sidelobe of the spectra and reducing channel crosstalk. 

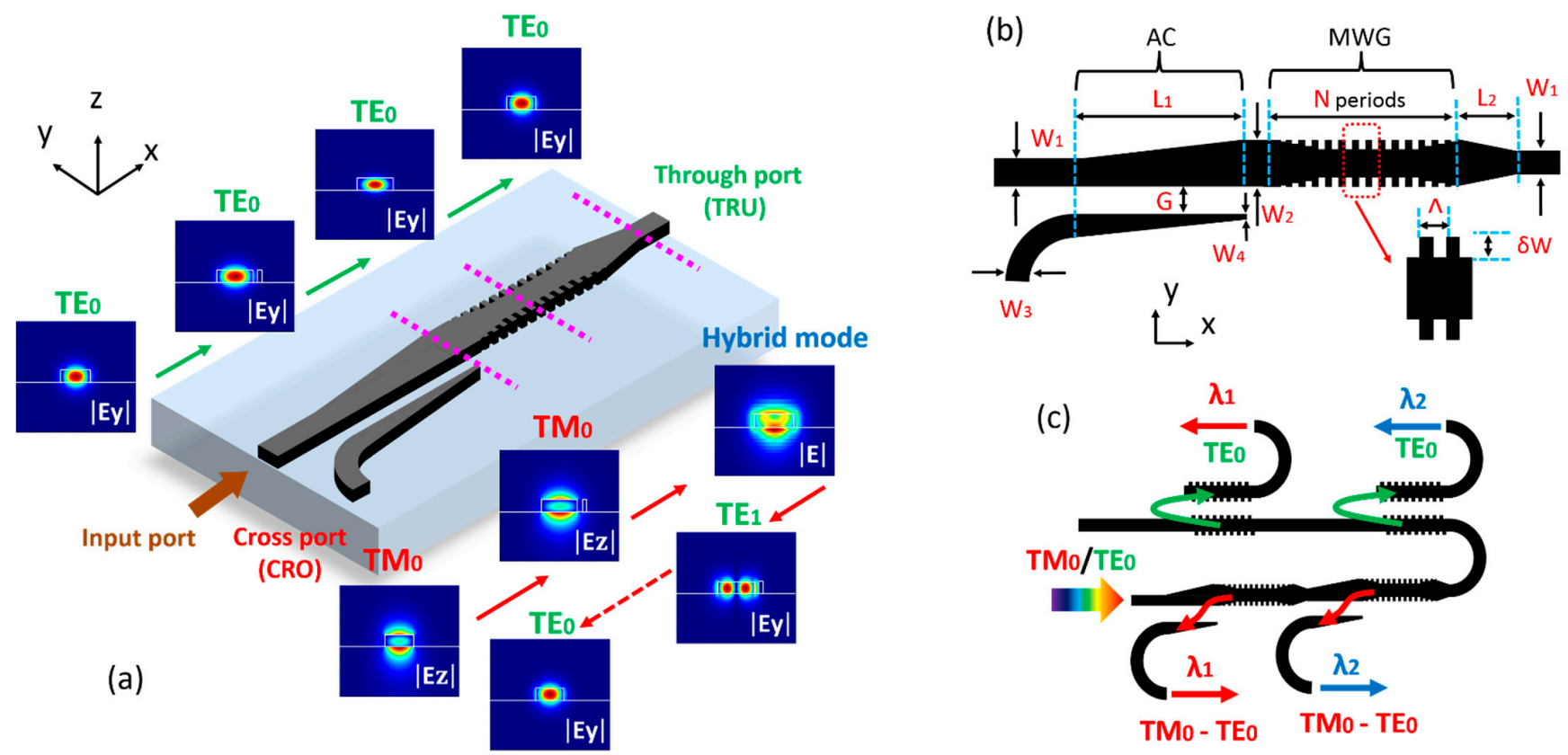

Figure 1. Schematic configuration of the proposed PSR. (a) Three-dimensional structure and (b) top view of the device. (c) Architecture of polarization insensitive wavelength duplexer based on MWG-based PSRs and contra-DCs.

To illustrate the working principle of the proposed PSR, we calculated the photonic band structure of uniform MWG using the three-dimensional finite-difference time-domain (3D-FDTD) method, with structure parameters: $\Lambda=414 \mathrm{~nm}, \mathrm{~W}_{2}=900 \mathrm{~nm}, \delta \mathrm{w}=100 \mathrm{~nm}$, fill factor $\mathrm{ff}=0.5$. For the unit cell, non-uniform meshing is utilized with minimum mesh sizes $\Delta \mathrm{x}_{\min }=\Delta \mathrm{y}_{\min }=10 \mathrm{~nm}$, and $\Delta \mathrm{z}_{\min }=20 \mathrm{~nm}$. Bloch periodic boundary conditions are imposed on the two surfaces perpendicular to the $x$-axis, and perfectly matched layer (PML) boundary conditions are applied on the other surfaces. Figure 2a shows the band structure of $\mathrm{TE}_{0}, \mathrm{TE}_{1}$, and $\mathrm{TM}_{0}$ Bloch mode. The photonic band gaps (PBGs) are located at $187.8 \mathrm{THz}-190.2 \mathrm{THz}, 200.07 \mathrm{THz}-201.2 \mathrm{THz}$, respectively, which means that there is no allowed mode in uniform MWG. Anti-crossing between $\mathrm{TM}_{0}$ and $\mathrm{TE}_{1}$ modes can also be observed, giving rise to a MSB at frequencies ranging from $194.0 \mathrm{THz}$ to $195.3 \mathrm{THz}$ (or wavelengths from $1.536 \mu \mathrm{m}$ to $1.547 \mu \mathrm{m}$ ). Hence, the input $\mathrm{TM}_{0}$ mode located in MSB can be converted to backward $\mathrm{TE}_{1}$ Bloch mode, and vice-versa. Note that the conversion between the $\mathrm{TM}_{0}$ and $\mathrm{TE}_{1}$ Bloch modes in the uniform MWG should satisfy the phase matching condition: $\lambda_{c} / \Lambda=\left(\right.$ Neff $_{1}+$ Neff $\left._{2}\right)$, where Neff 1 and Neff 2 represent the effective refractive indices of the two coupled Bloch modes, and $\lambda_{c}$ is central wavelength. The group indices $\mathrm{Ng}_{T E 1}$ and $\mathrm{Ng}_{T M 0}$ of both modes can be extracted from the slope of their dispersion relation, taken far from the coupling region [27]. The value of coupling coefficient $\mathcal{k}$ can be derived by the following expression [39]:

$$
\kappa=\pi N_{g} \Delta \lambda / \lambda_{c}^{2}
$$

where $\Delta \lambda$ is bandwidth of MSB, and $N_{g}=\left(N_{g T E 0}+N_{g T M 1}\right) / 2$. For the uniform MWG considered above, the parameters extracted from the dispersion diagram of Figure 2a are $N g_{T E 1}=5.05, N g_{T M 0}=4.11$, and $\Delta \lambda / \lambda_{c}^{2}=0.463 \times 10^{3} \mathrm{~m}^{-1}$, leading to $\kappa=6.66 \times 10^{3} \mathrm{~m}^{-1}$. This value is lower than the one of common waveguide Bragg gratings without polarization conversion, typically $>50 \times 10^{3} \mathrm{~m}^{-1}$ [40]. Additionally, we can effectively tune $\kappa$ by using lateral phase delay modulation [41], for the purpose of apodization design. Figure $2 b$ shows the local picture of MSB associated to the coupling between $\mathrm{TM}_{0}$ and $\mathrm{TE}_{1}$ Bloch modes. The electric field patterns are represented in Figure 2c,d. 

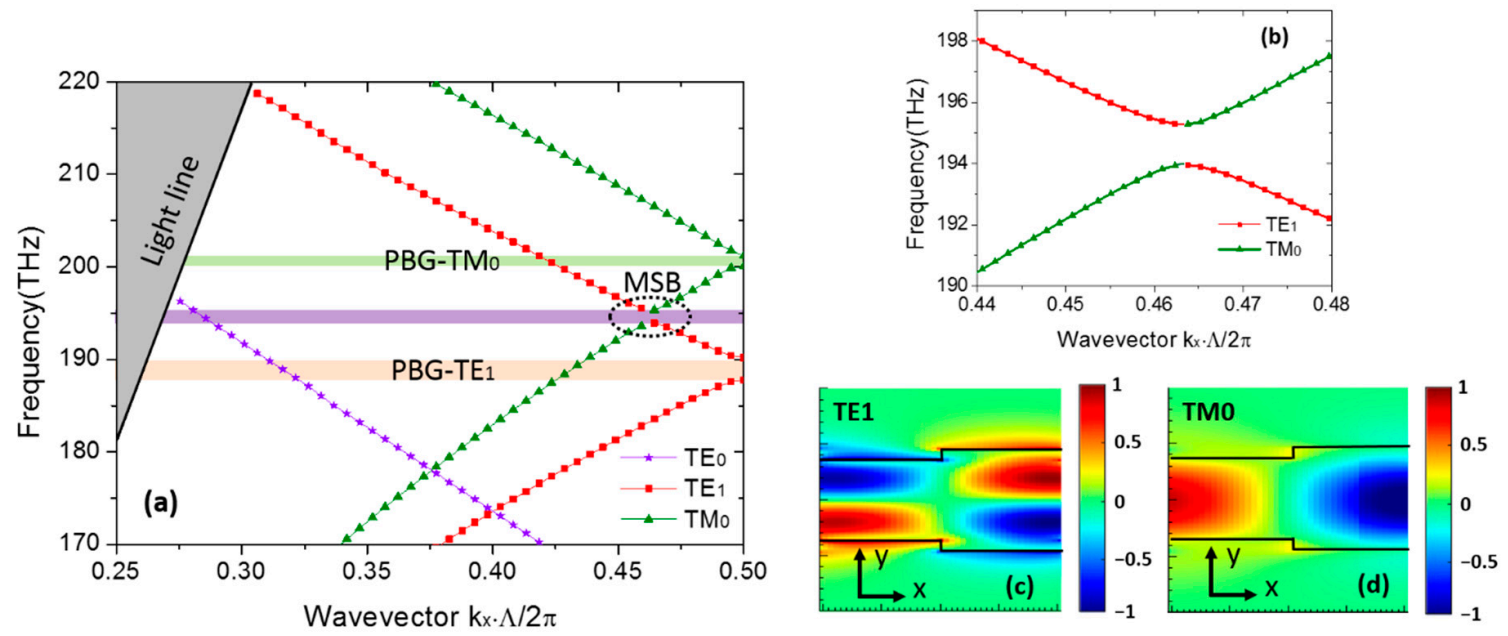

Figure 2. (a) Photonic band structure of uniform MWG. (b) Local picture of MSB associated to the coupling of $\mathrm{TM}_{0}$ mode and $\mathrm{TE}_{1}$ mode. Electric field patterns associated to (c) $\mathrm{TE}_{1}$ mode (y-component, $\mathrm{E}_{\mathrm{y}}$ ) and (d) $\mathrm{TM}_{0}$ mode (z-component, $\mathrm{E}_{\mathrm{z}}$ ).

Figure 3a shows the transmission and reflection spectra of uniform MWG with $\mathrm{N}=100$ when $\mathrm{TE}_{0}$ and $\mathrm{TM}_{0}$ mode are injected. The results are calculated using uniform meshing with $\Delta \mathrm{x}_{\min }=\Delta \mathrm{y}_{\min }=\Delta \mathrm{z}_{\min }=20 \mathrm{~nm}$, which ensure accuracy and calculation efficiency. One MSB ranging from $1.541 \mu \mathrm{m}$ to $1.551 \mu \mathrm{m}$ is observed; the reflection of the $\mathrm{TM}_{0}$ mode is about $96 \%$. We note that the transmission of input $\mathrm{TE}_{0}$ mode is near $96 \%$ in $\mathrm{MSB}$, while the major component of backward fields is $\mathrm{TM}_{1}$ mode. However, this crosstalk is negligible due to the weak reflection and large propagation loss of $\mathrm{TM}_{1}$ mode for the proposed device.

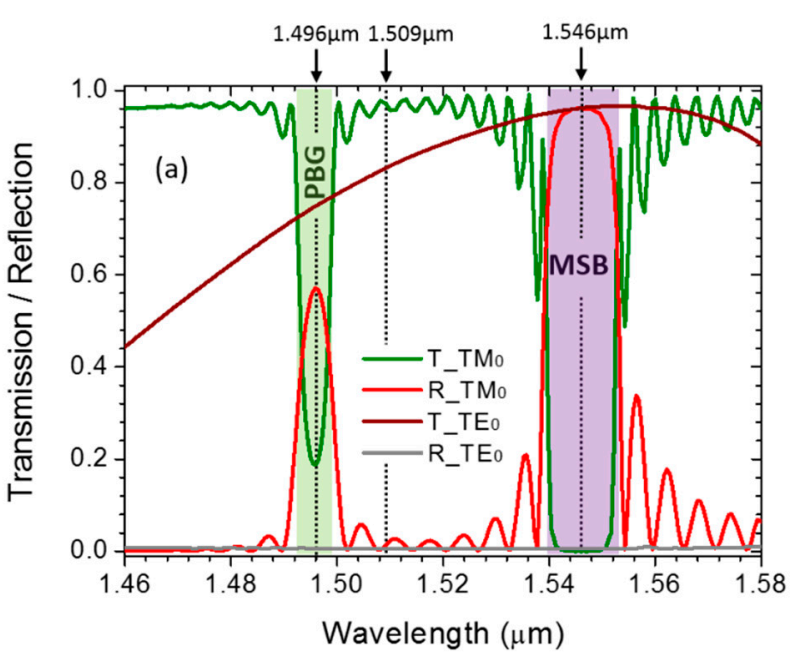

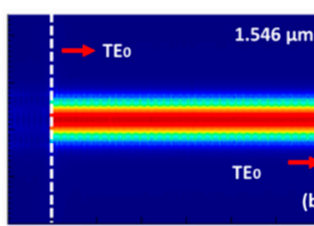
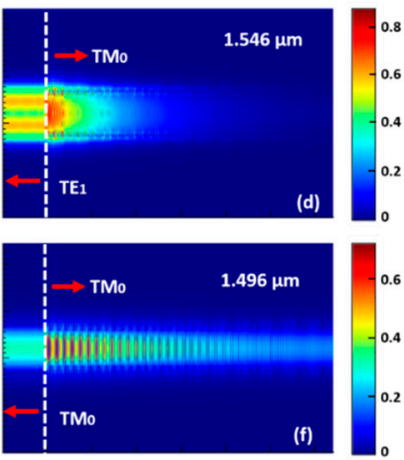
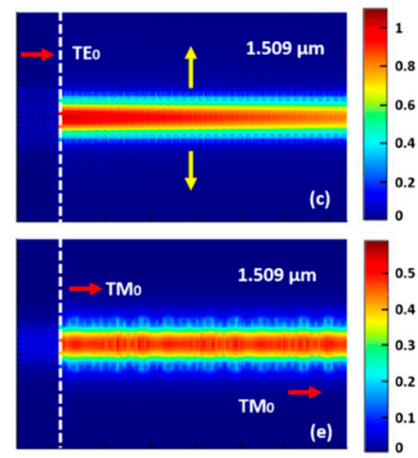
(e) 0.1

Figure 3. (a) Transmission and reflection spectra of uniform MWG. The light propagation profiles (electric field intensity $|\mathrm{E}|)$ in uniform MWG section when $\mathrm{TE}_{0}$ mode and $\mathrm{TM}_{0}$ mode are injected, at wavelengths of $(\mathbf{b}, \mathbf{d}) 1.546 \mu \mathrm{m},(\mathbf{c}, \mathbf{e}) 1.509 \mu \mathrm{m}$, and (f) $1.496 \mu \mathrm{m}$.

We further simulate light propagation profiles in uniform MWG using 3D-FDTD, at typical wavelengths of $1.546 \mu \mathrm{m}, 1.509 \mu \mathrm{m}$, and $1.496 \mu \mathrm{m}$, which are presented in Figure $3 b-f$. As predicted in the band structure, the launched $\mathrm{TE}_{0}$ mode can maintain its polarization and propagate through uniform MWG (Figure 3b), at a wavelength of $1.546 \mu \mathrm{m}$. Meanwhile, the $\mathrm{TE}_{0}$ mode will be gradually attenuated as a radiation mode being located above the light line (Figure 3c), at a wavelength of $1.509 \mu \mathrm{m}(198.8 \mathrm{THz})$, with a transmission of $83 \%$. For the launched $\mathrm{TM}_{0}$ mode at $1.546 \mu \mathrm{m}$, the major component of backward field is $\mathrm{TE}_{1}$ mode, as shown in Figure $3 \mathrm{~d} . \mathrm{TM}_{0}$ mode is gradually attenuated 
at a wavelength of $1.496 \mu \mathrm{m}$ due to being located in the PBG (Figure 3f), while freely propagating at a wavelength of $1.509 \mu \mathrm{m}$ as a purely Bragg-guided mode (Figure 3e).

To reduce insertion loss and suppress back-reflection incurred by mode mismatch between strip waveguide and uniform MWG, two linearly tapered gratings are utilized at both ends of the uniform MWG with minimum sidewall corrugation $\delta \mathrm{w}_{\mathrm{min}}$, minimum period $\Lambda_{\min }$, and grating number $\mathrm{N}^{\prime}$, as seen in Figure $4 \mathrm{a}$. The $\mathrm{TM}_{0}-\mathrm{TE}_{1}$ conversion efficiency is equal to the fraction of power reflected into $\mathrm{TE}_{1}$ mode, which can be extracted utilizing the Mode Expansion Monitor. The transmission and reflection as a function of $\Lambda_{\min }$ are shown in Figure $4 \mathrm{~b}$. We can see that there is a linear variation region $\left(340 \mathrm{~nm}<\Lambda_{\min }<390 \mathrm{~nm}\right)$ for $\mathrm{TE}_{0}$ mode, and a local minimum reflection of $-46 \mathrm{~dB}$ for $\mathrm{TM}_{0}$ mode when $\Lambda_{\min }=380$ $\mathrm{nm}$, which corresponds to the highest $\mathrm{TM}_{0}-\mathrm{TE}_{1}$ conversion efficiency. This means that we need to make a trade-off between the transmission of $\mathrm{TE}_{0}$ mode and the reflection of $\mathrm{TM}_{0}$ mode. Here, the optimal $\Lambda_{\min }$ is determined to be $380 \mathrm{~nm}$, which guarantees an acceptable transmission of $94.2 \%$ for $\mathrm{TE}_{0}$ mode and the lowest reflection of $\mathrm{TM}_{0}$ mode, and the highest conversion efficiency of $\mathrm{TM}_{0}-\mathrm{TE}_{1}$. In the following simulation, linearly tapered gratings with $\delta \mathrm{w}_{\min }=10 \mathrm{~nm}, \Lambda_{\min }=380 \mathrm{~nm}$ and $\mathrm{N}^{\prime}=20$ are adopted.

(a)

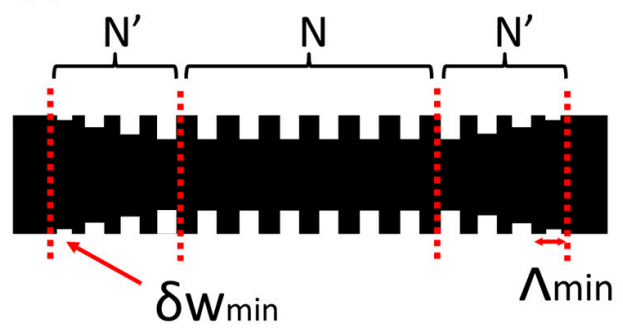

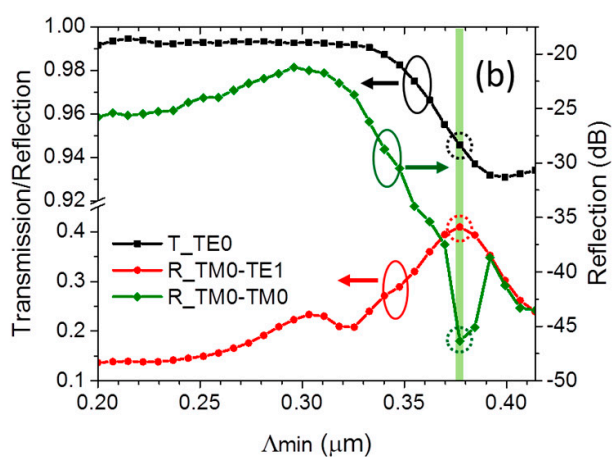
Figure 4. (a) The schematic of linearly tapered MWG. (b) The transmission and reflection of linearly
tapered MWG as a function of $\Lambda_{\min }$, at $1.546 \mu \mathrm{m}$. Calculation using the following parameters: $\Lambda=414 \mathrm{~nm}, \mathrm{~W}_{2}=900 \mathrm{~nm}, \delta \mathrm{W}=100 \mathrm{~nm}, \mathrm{ff}=0.5, \mathrm{~N}=10$ for the uniform MWG and $\delta \mathrm{w}_{\min }=10 \mathrm{~nm}$, $\mathrm{N}^{\prime}=20$ for the taper section.

We investigate the influence of grating number $\mathrm{N}$ on spectra, keeping $\Lambda=0.414 \mu \mathrm{m}$, $\mathrm{W}_{2}=0.9 \mu \mathrm{m}, \delta \mathrm{w}=0.1 \mu \mathrm{m}$, and $\mathrm{ff}=50 \%$, as shown in Figure $5 \mathrm{a}$. It is seen that as $\mathrm{N}$ increases, the stopband edge becomes much steeper, and the maximum reflection increases significantly. Figure $5 \mathrm{~b}$ presents the conversion efficiency and transmission as a function of grating number. As seen, the transmission of $\mathrm{TE}_{0}$ mode is higher than $92 \%(-0.36 \mathrm{~dB})$ when $\mathrm{N}=200$, and the conversion efficiency of $\mathrm{TM}_{0}-\mathrm{TE}_{1}$ is improved by up to $98 \%(-0.22 \mathrm{~dB})$. The transmission of $\mathrm{TM}_{0}$ mode is about $-46.9 \mathrm{~dB}$ at $1.546 \mu \mathrm{m}$, which could be even lower by increasing the grating number.
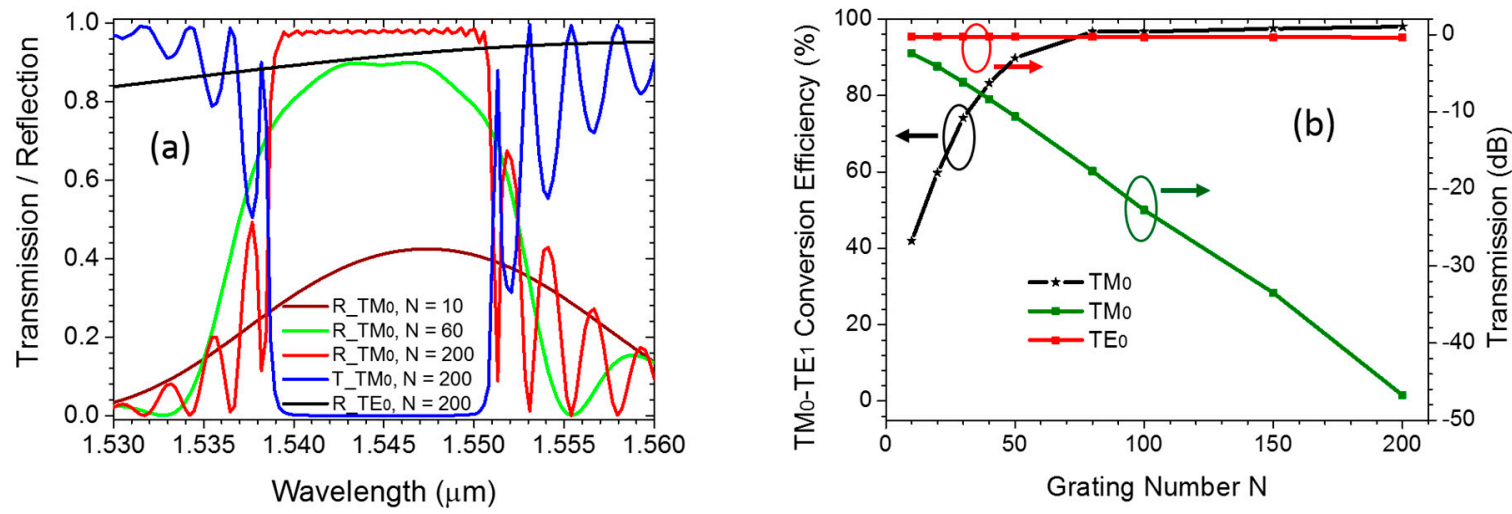

Figure 5. (a) The transmission and reflection spectra of linearly tapered MWG with different $\mathrm{N}$. (b) $\mathrm{TM}_{0}-\mathrm{TE}_{1} \mathrm{Conversion}$ efficiency as a function of grating number $\mathrm{N}$ at $1.546 \mu \mathrm{m}$. 
Next, we change the grating period $\Lambda$ while keeping $W_{2}=0.9 \mu \mathrm{m}, \delta \mathrm{w}=0.1 \mu \mathrm{m}$ and $\mathrm{N}=200$. The reflection spectra shown in Figure $6 \mathrm{a}$ indicates that stopband is red-shifted significantly as $\Lambda$ increases. Slight ripple (lower than 1\%) in stopband caused by mode mismatch is observed. Figure $6 \mathrm{~b}$ presents the dependence of central wavelength $\lambda c$ and $1-\mathrm{dB}$ bandwidth on grating period quantitatively. As seen, when $\Lambda$ increases from $0.414 \mu \mathrm{m}$ to $0.432 \mu \mathrm{m}, \lambda c$ increases linearly from $1.545 \mu \mathrm{m}$ to $1.573 \mu \mathrm{m}$ with slope $\frac{d \lambda c}{d \Lambda}=1.5$, and the bandwidth increases monotonously from $13 \mathrm{~nm}$ to $15 \mathrm{~nm}$. Therefore, one can design operation wavelength of PSR by tuning grating period.
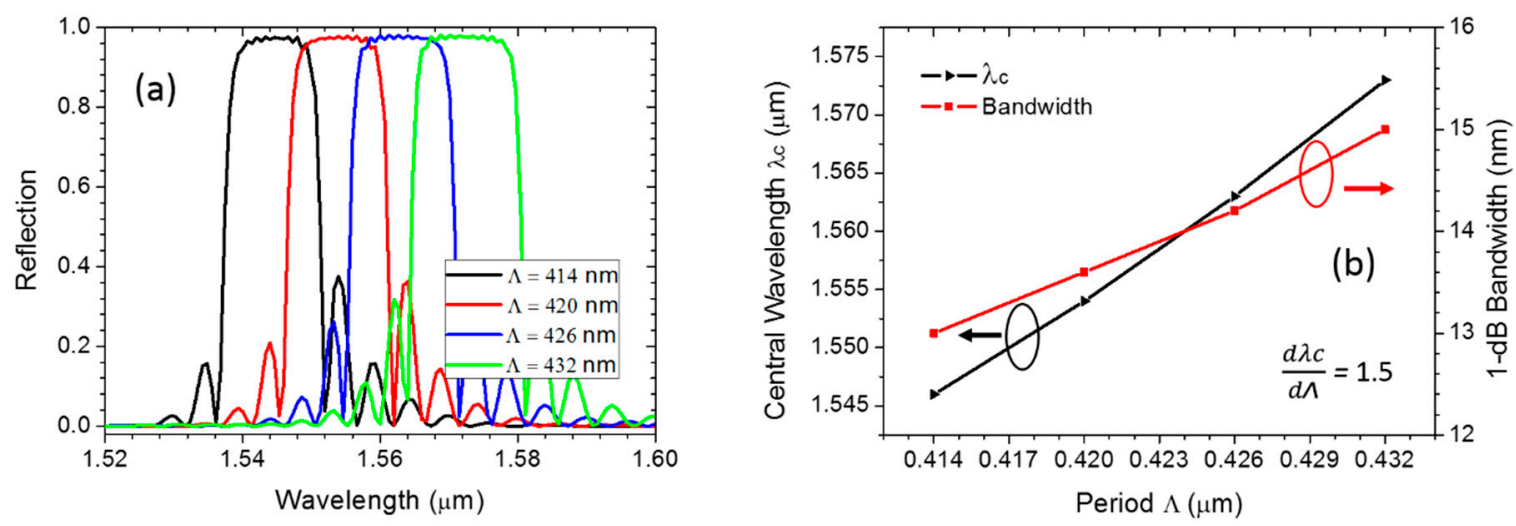

Figure 6. (a) The reflection spectra of linearly tapered MWG with different period $\Lambda$. (b) The central wavelength $\lambda c$ and bandwidth $(90 \% \mathrm{CE})$ as a function of grating period $\Lambda$ at wavelength of $1.546 \mu \mathrm{m}$.

The effect of corrugation width $\delta \mathrm{w}$ on reflection spectra is investigated when $\mathrm{W}_{2}$ $=0.9 \mu \mathrm{m}, \Lambda=0.414 \mu \mathrm{m}$, and $\mathrm{N}=200$. As shown in Figure 7a, the stopband is red-shifted significantly as $\delta \mathrm{w}$ decreases, due to a variation of the effective refractive index in MWG. The reflection of central wavelength is diminished from 0.98 to 0.8 because of the decreasing grating strength. Figure $7 \mathrm{~b}$ presents the dependence of central wavelength $\lambda c$ and $1-\mathrm{dB}$ bandwidth of the stopband on the $\delta \mathrm{w}$ quantitatively. As seen, when $\delta \mathrm{w}$ increases from $50 \mathrm{~nm}$ to $112.5 \mathrm{~nm}, \lambda c$ decreases with $\delta \mathrm{w}$ linearly from $1.578 \mu \mathrm{m}$ to $1.535 \mu \mathrm{m}$ with a slope $\frac{d \lambda c}{d \delta \mathrm{w}}=-0.693$, and the $1-\mathrm{dB}$ bandwidth increases monotonously from $6 \mathrm{~nm}$ to $14 \mathrm{~nm}$. This indicates that the MWG-based PSR is intrinsically characterized by a narrow operation bandwidth, due to the wavelength dependence of the grating.
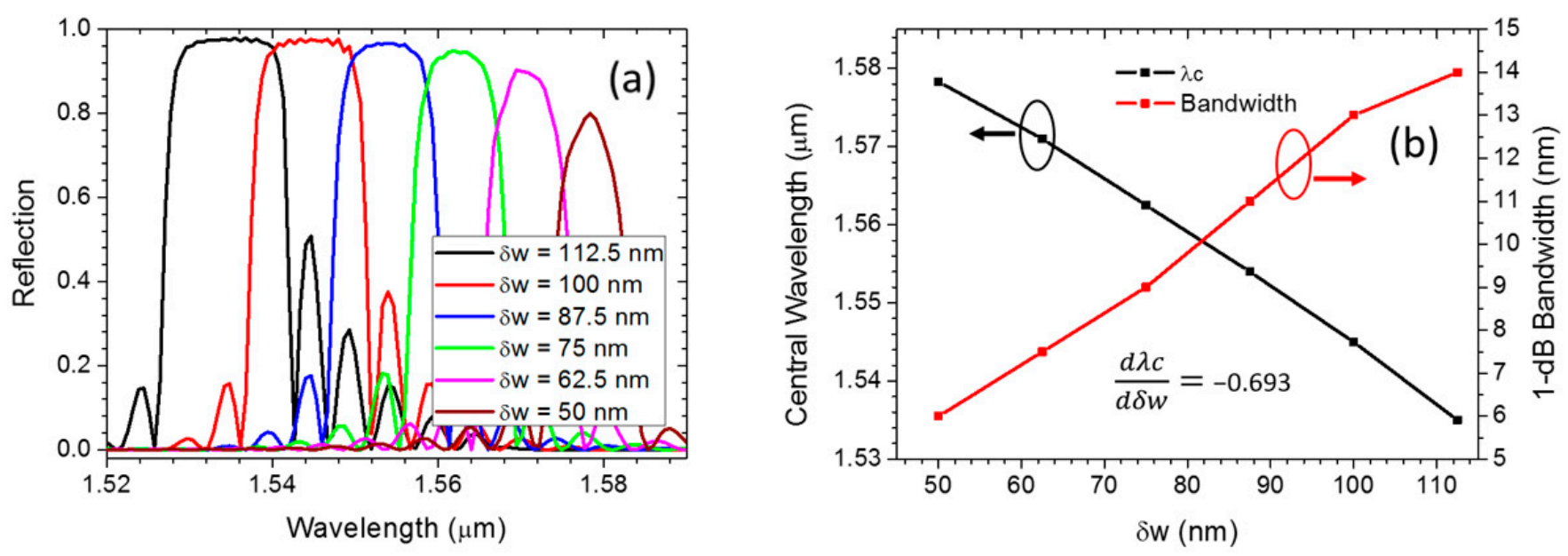

Figure 7. (a) The reflection spectra of linearly tapered MWG with different corrugation width $\delta w$. (b) The central wavelength and $1 \mathrm{~dB}$ bandwidth as a function of $\delta \mathrm{w}$. 


\section{Device Performance and Analysis}

An adiabatic coupler is adopted for the conversion between backward $\mathrm{TE}_{1}$ mode and $\mathrm{TE}_{0}$ mode because of its high conversion efficiency and large fabrication tolerance. The design parameters of $\mathrm{AC}$ and linear taper are optimized by the Eigenmode expansion (EME) method, which are listed as follows: $\mathrm{W}_{1}=0.7 \mu \mathrm{m}, \mathrm{W}_{2}=0.9 \mu \mathrm{m}, \mathrm{W}_{3}=0.4 \mu \mathrm{m}$, $\mathrm{W}_{4}=0.1 \mu \mathrm{m}, \mathrm{G}=0.12 \mu \mathrm{m}, \mathrm{L}_{1}=160 \mu \mathrm{m}, \mathrm{L}_{2}=3 \mu \mathrm{m}$. The $\mathrm{TE}_{1}$ to $\mathrm{TE}_{0}$ conversion efficiency is up to $98.5 \%$ when $L_{1}=160 \mu \mathrm{m}$ at wavelength of $1.546 \mu \mathrm{m}$, as shown in Figure 8. Meanwhile, the mode conversion efficiency between the forward $\mathrm{TM}_{0}$ mode and $\mathrm{TE}_{1}$ mode decreases significantly, owing to the taper width (from $\mathrm{W}_{1}$ to $\mathrm{W}_{2}$ ), which is far away from the mode hybridization region, about $660 \mathrm{~nm}$ for the case of air cladding [22].
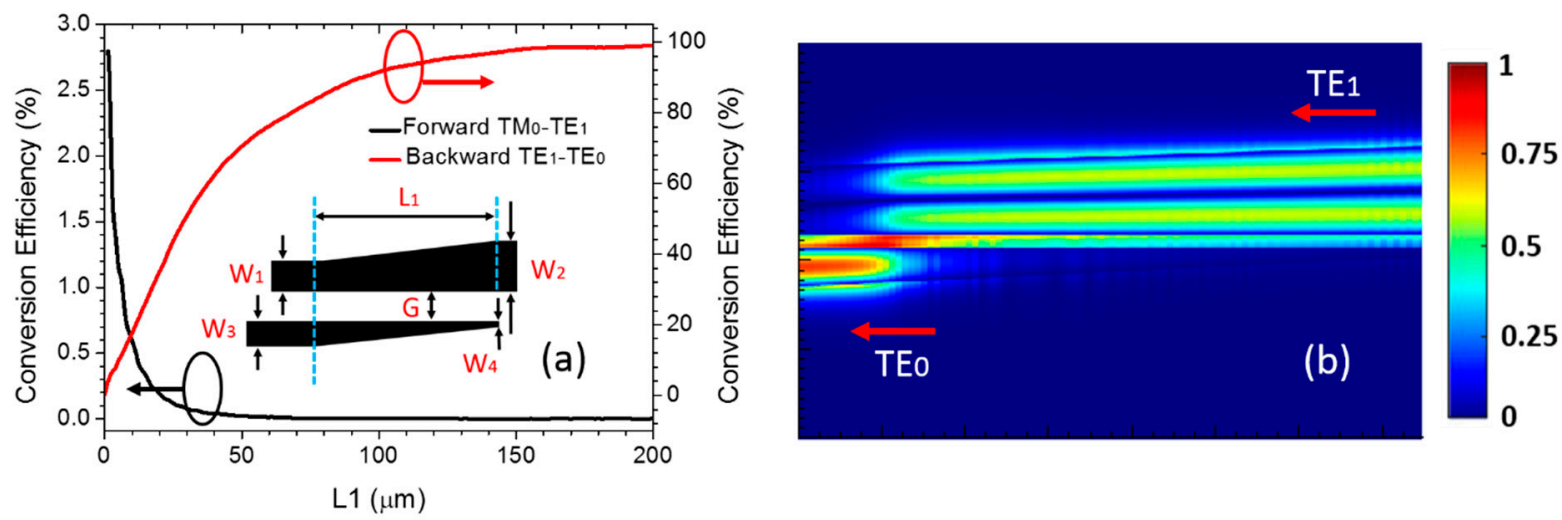

Figure 8. (a) The conversion efficiency of forward $\mathrm{TM}_{0}-\mathrm{TE}_{1}$ and backward $\mathrm{TE}_{1}-\mathrm{TE}_{0}$, in $\mathrm{AC}$ section. (b) Simulated light propagation profiles (electric field intensity $|\mathrm{E}|$ ) in adiabatic coupler when $\mathrm{TE}_{1}$ mode propagates backward.

The light propagation profiles and transmission spectra of the whole PSR are simulated using structure parameters as following: $\mathrm{W}_{1}=0.7 \mu \mathrm{m}, \mathrm{W}_{2}=0.9 \mu \mathrm{m}, \mathrm{W}_{3}=0.4 \mu \mathrm{m}$, $\mathrm{W}_{4}=0.1 \mu \mathrm{m}, \mathrm{L}_{1}=160 \mu \mathrm{m}, \mathrm{L}_{2}=3.0 \mu \mathrm{m}, \mathrm{G}=0.12 \mu \mathrm{m}, \mathrm{N}=200, \delta \mathrm{W}=0.1 \mu \mathrm{m}, \Lambda=0.414 \mu \mathrm{m}$, $\mathrm{ff}=0.5, \delta \mathrm{w}_{\min }=10 \mathrm{~nm}, \Lambda_{\min }=380 \mathrm{~nm}$ and $\mathrm{N}^{\prime}=20$. As shown in Figure $9 \mathrm{a}, \mathrm{b}$, the injected $\mathrm{TE}_{0}$ mode propagates through the whole structure and outputs at the TRU port. Meanwhile, the injected $\mathrm{TM}_{0}$ mode is first reversely converted to be $\mathrm{TE}_{1}$ mode in the MWG section, then coupled to be $\mathrm{TE}_{0}$ mode in the narrow waveguide of $\mathrm{AC}$ section, and finally output at the CRO port. The proposed PSR is evaluated by the performance metrics of insertion loss (IL), extinction ratio (ER), and crosstalk (CT), respectively [42]. The IL, ER, and CT for input $\mathrm{TE}_{0}$ mode are defined as:

$$
\begin{gathered}
\mathrm{IL}_{\mathrm{TE}}=-10 \cdot \log _{10}\left(\mathrm{~T}_{\mathrm{TE}}^{\mathrm{tru}}\right) \\
\mathrm{ER}_{\mathrm{TE}}=-10 \cdot \log _{10}\left(\mathrm{~T}_{\mathrm{TM}}^{\mathrm{tru}} / \mathrm{T}_{\mathrm{TE}}^{\mathrm{tru}}\right) \\
\mathrm{CT}_{\mathrm{TE}}=10 \cdot \log _{10}\left(\mathrm{~T}_{\mathrm{TE}}^{\mathrm{cro}} / \mathrm{T}_{\mathrm{TE}}^{\mathrm{tru}}\right)
\end{gathered}
$$

The IL, ER and CT for input $\mathrm{TM}_{0}$ mode are defined as:

$$
\begin{gathered}
\mathrm{IL}_{\mathrm{TM}}=-10 \cdot \log _{10}\left(\mathrm{~T}_{\mathrm{TE}}^{\mathrm{cro}}\right) \\
\mathrm{ER}_{\mathrm{TM}}=-10 \cdot \log _{10}\left(\mathrm{~T}_{\mathrm{TM}}^{\mathrm{cro}} / \mathrm{T}_{\mathrm{TE}}^{\mathrm{cro}}\right) \\
\mathrm{CT}_{\mathrm{TM}}=10 \cdot \log _{10}\left(\mathrm{~T}_{\mathrm{TE}}^{\mathrm{tru}} / \mathrm{T}_{\mathrm{TE}}^{\mathrm{cro}}\right)
\end{gathered}
$$

where $\mathrm{T}_{\text {mode }}^{\text {port }}$ means the transmission of mode at TRU port or CRO port. The calculated transmission spectra are shown in Figure $9 \mathrm{c}, \mathrm{d}$; we note that the $\mathrm{IL}_{\mathrm{TE}}$ and $\mathrm{IL}_{\mathrm{TM}}$ are both less than $0.5 \mathrm{~dB}$ over $10 \mathrm{~nm}$ bandwidth $(1.54 \mu \mathrm{m}-1.55 \mu \mathrm{m})$. The $\mathrm{ER}_{\mathrm{TE}}$ is $>50 \mathrm{~dB}$ and $\mathrm{CT}_{\mathrm{TE}}$ is < $-39 \mathrm{~dB}$ for the $\mathrm{TE}_{0}$ mode in the wavelength range of $1.53 \mu \mathrm{m}-1.56 \mu \mathrm{m}$. Note that $\mathrm{CT}_{\mathrm{TE}}$ is theoretically originated from the backward $\mathrm{TM}_{1}$ mode excited by MWG. However, this impact is negligible for a fabricated device considering the large propagation loss of $\mathrm{TM}_{1}$ 
mode, which is further confirmed by our experimental results. For the input $\mathrm{TM}_{0}$ mode, $\mathrm{ER}_{\mathrm{TM}}$ of $>30 \mathrm{~dB}$ and $\mathrm{CT}_{\mathrm{TM}}$ of $-48 \mathrm{~dB}$ can be observed, ranging from $1541 \mathrm{~nm}$ to $1550 \mathrm{~nm}$. The $\mathrm{ER}_{\mathrm{TM}}$ is originated from the weakly reflected $\mathrm{TM}_{0}$ mode.
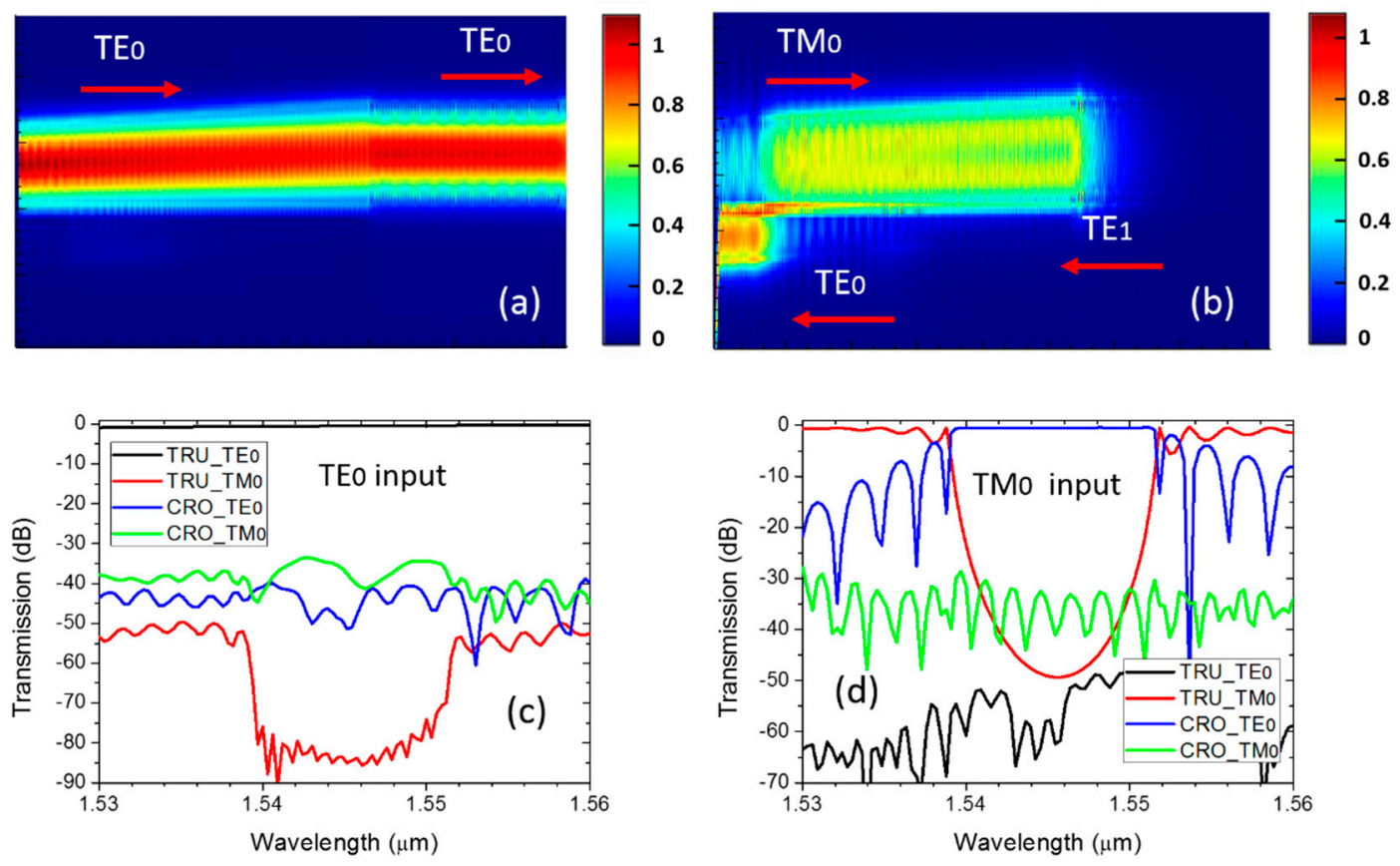

Figure 9. The light propagation profiles (electric field intensity $|\mathrm{E}|$ ) for the PSR when (a) $\mathrm{TE}_{0} \operatorname{mode}$ and (b) $\mathrm{TM}_{0} \mathrm{mode}$ are launched at wavelength of $1.546 \mu \mathrm{m}$. The simulated transmission spectra of the proposed PSR when (c) TE $\mathrm{T}_{0}$ mode and (d) $\mathrm{TM}_{0}$ mode are launched.

We further investigate the fabrication tolerance of the proposed PSR, assuming there is a width variation of $W_{2}$ and corrugation $\delta \mathrm{w}$. As shown in Figure $10 \mathrm{a}$, when $\mathrm{TM}_{0}$ mode is launched, the PSR exhibits a performance of $<0.5 \mathrm{~dB}$ IL and $>30 \mathrm{dBCT}$, when $\Delta \mathrm{W}_{2}$ changes from $-10 \mathrm{~nm}$ to $10 \mathrm{~nm}$. The reason can be explained by the fact that the effective refractive index in MWG is sensitive to the width variation; therefore, the phase-match condition and stopband are affected. However, the transmission of $\mathrm{TE}_{0}$ mode (Figure 10b) is only slightly affected by $\Delta \mathrm{W}_{2}$; the $\mathrm{CT}$ is $>36 \mathrm{~dB}$, and IL is $<0.6 \mathrm{~dB}$, showing a robust performance. The device performance affected by the corrugation width $\delta \mathrm{w}$ is shown in Figure $10 \mathrm{c}, \mathrm{d}$. For the $\mathrm{TM}_{0}$ mode, a high $\mathrm{CT}$ of $>20 \mathrm{~dB}$ is obtained, when $\Delta \delta \mathrm{w}$ varies from $-7.5 \mathrm{~nm}$ to $7.5 \mathrm{~nm}$, assuming $\mathrm{W}_{2}=0.9 \mu \mathrm{m}$. However, this influence is slight for $\mathrm{TE}_{0}$ mode (Figure 10d). Overall, the proposed PSR exhibits different performance according to the structure variations, for $\mathrm{TE}_{0}$ mode and $\mathrm{TM}_{0}$ mode, respectively. Additionally, for the injected $\mathrm{TM}_{0}$ mode, the influence of $\Delta \delta \mathrm{w}$ is more significant than $\Delta \mathrm{W}_{2}$. The proposed device can be fabricated by advanced fabrication technologies. 

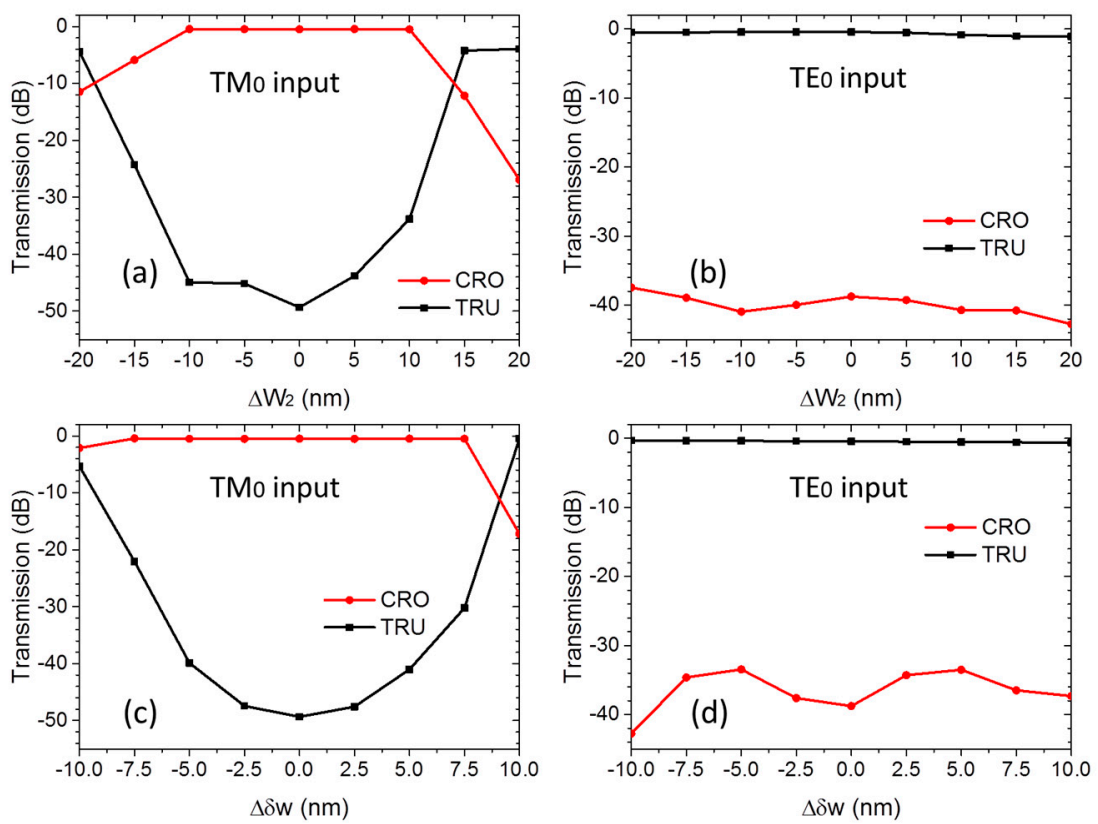

Figure 10. Dependence of transmission on $(\mathbf{a}, \mathbf{b})$ width deviation $\Delta \mathrm{W}_{2}$ and $(\mathbf{c}, \mathbf{d})$ corrugation width deviation $\Delta \delta \mathrm{w}$ for $\mathrm{TE}_{0}$ and $\mathrm{TM}_{0}$ incidence at wavelength of $1.546 \mu \mathrm{m}$.

\section{Fabrication and Measurement}

We fabricated the proposed PSR on the SOI platform with a $220 \mathrm{~nm}$ thick silicon layer and a $2 \mu \mathrm{m}$ thick oxide layer. The silicon waveguides were first patterned via electron beam lithography (EBL), then etched by the inductively coupled plasma (ICP) etching process. The focused TM grating couplers (pitch $=1.19 \mu \mathrm{m}$, duty cycle $=0.5$ ) and linearly tapered TE grating couplers (pitch $=0.662 \mu \mathrm{m}$, duty cycle $=0.5$ ) were adopted for fiberchip coupling and polarization selectivity, with the same coupling angle of $20^{\circ}$. To make a full characterization for different polarization conversion scenarios, four sets of PSRs with TE/TM grating couplers at the input/output ports were fabricated, as shown in Figure 11a. It should be noted that the length of AC was chosen as $350 \mu \mathrm{m}$ for complete mode conversion [4]. Figure 11b,c show the scanning electric microscopy (SEM) image of the taper and uniform grating section. We can see that the taper section and the designed corrugations on MWG have been accurately fabricated.

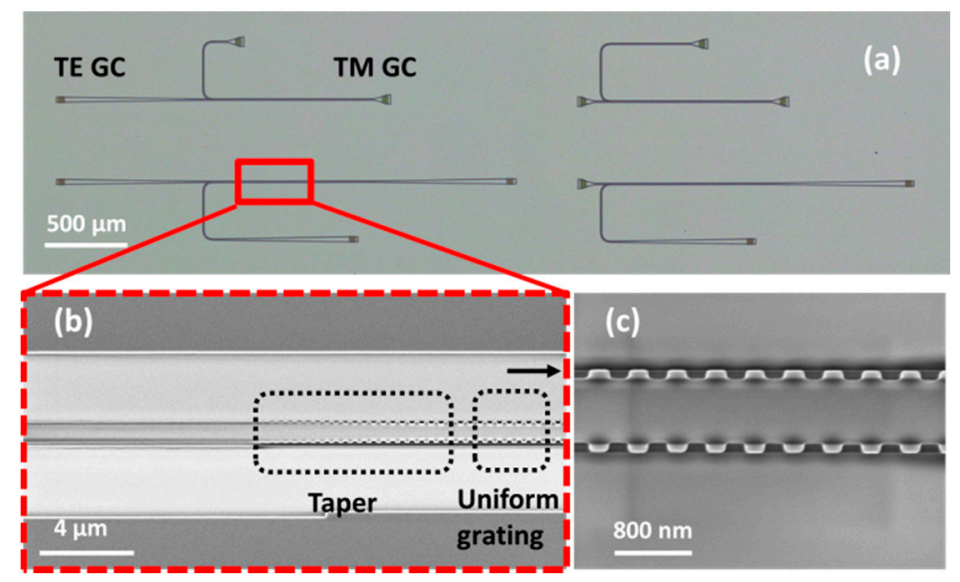

Figure 11. (a) The microscope image for the fabricated PSR. The scanning electric microscopy (SEM) image for (b) linearly taper section and (c) zoom-in of uniform grating section.

To experimentally characterize the fabricated devices, light was first generated from a C-band tunable laser, with its polarization state controlled by a polarization controller. 
The position and angle of the two coupling fibers were aligned utilizing two six-axis stages. The laser source and power meter were connected by a computer to implement wavelength sweeping and power data recording. Figure 12a,b show the measured transmission spectra of the fabricated PSR when $\mathrm{TE}_{0}$ mode and $\mathrm{TM}_{0}$ mode are launched, which are normalized with respect to the transmission of grating couplers on the same chip. As depicted in Figure $12 \mathrm{a}$, the $\mathrm{TE}_{0}$ mode propagates to the TRU port with average $\mathrm{IL}_{\mathrm{TE}}$ of $1.2 \mathrm{~dB}$. The $\mathrm{ER}_{\mathrm{TE}}$ is $>53 \mathrm{~dB}$ and $\mathrm{CT}_{\mathrm{TE}}$ is $<-26.4 \mathrm{~dB}$, around the central wavelength of $1555 \mathrm{~nm}$. As shown in Figure 12b, when the $\mathrm{TM}_{0}$ mode is launched, light outputs from the $\mathrm{CRO}$ port; the average $\mathrm{IL}_{\mathrm{TM}}$ is $1.5 \mathrm{~dB}, \mathrm{ER}_{\mathrm{TM}}$ of $>31 \mathrm{~dB}$, and $\mathrm{CT}_{\mathrm{TM}}$ of $>-30 \mathrm{~dB}$ can be observed ranging from $1552 \mathrm{~nm}$ to $1562 \mathrm{~nm}$. We can also observe about $10 \mathrm{~nm}$ central wavelength shifting, compared with the simulation results, which comes from the fabrication errors such as the variation of waveguide width, corrugation width, or waveguide thickness.
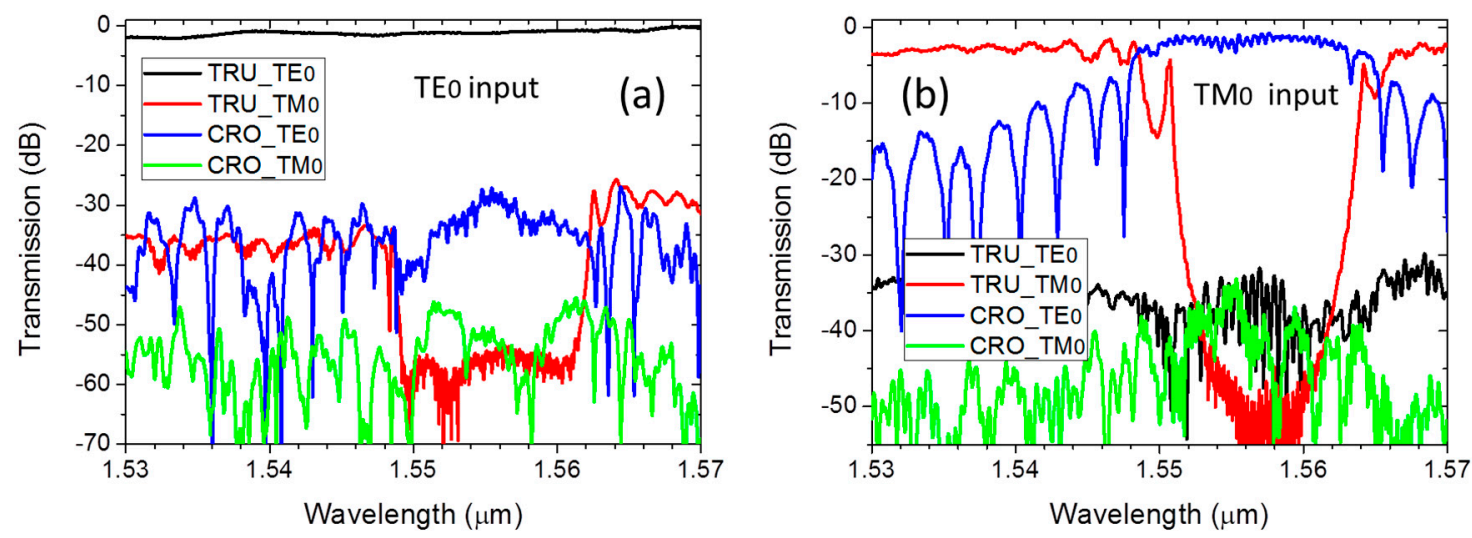

Figure 12. (a) Measured transmission spectra of the fabricated PSRs at through port and (b) cross port when $\mathrm{TE}_{0}$ and $\mathrm{TM}_{0}$ mode are launched.

\section{Conclusions}

In summary, we have presented a novel PSR based on MWG, on the SOI platform. Bloch mode hybridization in MSB is exploited to achieve a high polarization conversion efficiency. The fabricated devices exhibit a high extinction ratio of $>53 \mathrm{~dB}$ and $>31 \mathrm{~dB}$, low crosstalk of $<-26.4 \mathrm{~dB}$ and $<-40 \mathrm{~dB}$ for the injected $\mathrm{TE}_{0}$ and $\mathrm{TM}_{0}$ mode around the central wavelength. We believe that the proposed PSR could be applied in integrated polarization diversity circuits, especially for applications requiring spectra manipulation such as polarization insensitive wavelength division (de)multiplexer and multichannel polarizationmultiplexed differential quadrature phase-shift keying (PM-DQPSK) transceiver. Additionally, the polarization conversion approach provides opportunities to develop novel polarization management devices.

Author Contributions: Conceptualization, Y.L. (Yannong Luo) and X.C.; methodology, Y.L. (Yannong Luo), R.G. and H.L.; software, Y.L. (Yannong Luo) and R.G.; validation, Y.L. (Yannong Luo), L.Z. and M.A.; formal analysis, Y.L. (Yannong Luo), R.G. and W.L.; investigation, Y.L. (Yannong Luo) and J.Y.; resources, J.X.; data curation, Y.L. (Yannong Luo); writing-original draft preparation, Y.L. (Yannong Luo); writing-review and editing, Y.L. (Yannong Luo), M.W. and Q.L.; visualization, X.C.; supervision, Y.L. (Yongqing Li) and X.C.; project administration, Y.L. (Yannong Luo); funding acquisition, Y.L. (Yannong Luo) and X.C. All authors have read and agreed to the published version of the manuscript.

Funding: This work was supported by the National Key R\&D Program of China (2019YFB1803900, 2019YFA0705000); National Natural Science Foundation of China (11690031, 11761131001, 11904061); Key R\&D Program of Guangdong Province (2018B030329001); Local Innovative and Research Teams Project of Guangdong Pearl River Talents Program (2017BT01X121); Project of Key Laboratory of Radar Imaging and Microwave Photonics, Ministry of Education (RIMP2019003); Innovation Fund of WNLO (2018WNLOKF010); Guangzhou Science and Technology Program (201707010096); Guangxi youth and middle aged ability promotion project (2019KY0126); BaGui Scholar Program of Guangxi 
Province (02304002022C); China Postdoctoral Science Foundation (2020M673554XB); Guangdong Basic and Applied Basic Research Foundation (2020A1515010778).

Conflicts of Interest: The authors declare no conflict of interest.

\section{References}

1. Dai, D.; Bowers, J.E. Novel concept for ultracompact polarization splitter-rotator based on silicon nanowires. Opt. Exp. 2011, 19, 10940-10949. [CrossRef]

2. Dai, D.; Liu, L.; Gao, S.; Xu, D.X.; He, S. Polarization management for silicon photonic integrated circuits. Laser Photonics Rev. 2013, 7, 303-328. [CrossRef]

3. Doerr, C.; Chen, L.; Vermeulen, D.; Nielsen, T.; Azemati, S.; Stulz, S.; McBrien, G.; Xu, X.-M.; Mikkelsen, B.; Givehchi, M. Single-chip silicon photonics 100-Gb/s coherent transceiver. In Proceedings of the Optical Fiber Communication Conference, San Francisco, CA, USA, 9-13 March 2014; p. Th5C.1.

4. Sacher, W.D.; Barwicz, T.; Taylor, B.J.F.; Poon, J.K.S. Polarization rotator-splitters in standard active silicon photonics platforms. Opt. Exp. 2014, 22, 3777-3786. [CrossRef]

5. Wang, Y.; Ma, M.; Yun, H.; Lu, Z.; Wang, X.; Jaeger, N.A.; Chrostowski, L. Ultra-compact sub-wavelength grating polarization splitter-rotator for silicon-on-insulator platform. IEEE Photon. J. 2016, 8, 1-9. [CrossRef]

6. Keyvaninia, S.; Boerma, H.; Wössner, M.; Ganzer, F.; Runge, P.; Schell, M. Highly efficient passive InP polarization rotator-splitter. Opt. Exp. 2019, 27, 25872-25881. [CrossRef] [PubMed]

7. Chung, C.-J.; Midkiff, J.; Yoo, K.M.; Rostamian, A.; Guo, J.; Chen, R.T.; Chakravarty, S. InP-based polarization rotator-splitter for mid-infrared photonic integration circuits. AIP Adv. 2019, 9, 015303. [CrossRef]

8. Dai, X.; Lu, Q.; Guo, W. Fabrication-Tolerant Polarization Rotator-Splitter based on Silicon Nitride Platform. In Proceedings of the Optical Fiber Communication Conference, Washington, DC, USA, 6-11 June 2021; p. Th1A.31.

9. Chen, Z.; Pan, Y.; Liu, X.; Lin, H.; Zhong, X.; Cai, X. Single-step Etching Polarization Splitter-rotator based on Lithium Niobate Ridge Waveguide. In Proceedings of the Asia Communications and Photonics Conference, Chengdu, China, 2-5 November 2019; p. M4A.285.

10. Zhang, L.; Yang, S.; Zhang, G.; Fu, X.; Yang, L. Broadband $2 \times 2$ Polarization Splitter-Rotator Based on an Adiabatic Asymmetric Directional Coupler on the Lithium-Niobate-on-Insulator. In Proceedings of the Asia Communications and Photonics Conference, Beijing, China, 24-27 October 2020; p. M4A.176.

11. Tu, X.; Li, M.; Xing, J.; Fu, H.; Geng, D. Compact PSR based on an asymmetric bi-level lateral taper in an adiabatic directional coupler. J. Light. Technol. 2016, 34, 985-991. [CrossRef]

12. Wang, J.; Qi, M.; Xuan, Y.; Huang, H.; Li, Y.; Li, M.; Chen, X.; Jia, Q.; Sheng, Z.; Wu, A. Proposal for fabrication-tolerant SOI polarization splitter-rotator based on cascaded MMI couplers and an assisted bi-level taper. Opt. Exp. 2014, 22, 27869-27879. [CrossRef] [PubMed]

13. Bai, B.; Liu, L.; Zhou, Z. Ultracompact, high extinction ratio polarization beam splitter-rotator based on hybrid plasmonic-dielectric directional coupling. Opt. Lett. 2017, 42, 4752-4755. [CrossRef] [PubMed]

14. Chen, L.; Doerr, C.R.; Chen, Y.-K. Compact polarization rotator on silicon for polarization-diversified circuits. Opt. Lett. 2011, 36, 469-471. [CrossRef]

15. Guan, H.; Novack, A.; Streshinsky, M.; Shi, R.; Fang, Q.; Lim, A.E.-J.; Lo, G.-Q.; Baehr-Jones, T.; Hochberg, M. CMOS-compatible highly efficient polarization splitter and rotator based on a double-etched directional coupler. Opt. Exp. 2014, 22, 2489-2496. [CrossRef] [PubMed]

16. Dai, D.; Wu, H. Realization of a compact polarization splitter-rotator on silicon. Opt. Lett. 2016, 41, 2346-2349. [CrossRef] [PubMed]

17. Yin, Y.; Li, Z.; Dai, D. Ultra-broadband polarization splitter-rotator based on the mode evolution in a dual-core adiabatic taper. J. Light. Technol. 2017, 35, 2227-2233. [CrossRef]

18. Liu, L.; Ding, Y.; Yvind, K.; Hvam, J.M. Silicon-on-insulator polarization splitting and rotating device for polarization diversity circuits. Opt. Exp. 2011, 19, 12646-12651. [CrossRef]

19. Ding, Y.; Liu, L.; Peucheret, C.; Ou, H. Fabrication tolerant polarization splitter and rotator based on a tapered directional coupler. Opt. Exp. 2012, 20, 20021-20027. [CrossRef]

20. Tan, K.; Huang, Y.; Lo, G.-Q.; Lee, C.; Yu, C. Compact highly-efficient polarization splitter and rotator based on $90^{\circ}$ bends. Opt. Exp. 2016, 24, 14506-14512. [CrossRef]

21. Zafar, H.; Pereira, M.F.; Kennedy, K.L.; Anjum, D.H. Fabrication-tolerant and CMOS-compatible polarization splitter and rotator based on a compact bent-tapered directional coupler. AIP Adv. 2020, 10, 125214. [CrossRef]

22. Xu, H.; Shi, Y. Ultra-broadband silicon polarization splitter-rotator based on the multi-mode waveguide. Opt. Exp. 2017, 25, 18485-18491. [CrossRef]

23. Jeong, S.-H.; Onawa, Y.; Shimura, D.; Okayama, H.; Aoki, T.; Yaegashi, H.; Horikawa, T.; Nakamura, T. Polarization diversified $16 \lambda$ demultiplexer based on silicon wire delayed interferometers and arrayed waveguide gratings. J. Light. Technol. 2020, 38, 2680-2687. [CrossRef]

24. Onawa, Y.; Okayama, H.; Shimura, D.; Takahashi, H.; Yaegashi, H.; Sasaki, H. Polarisation insensitive wavelength de-multiplexer using arrayed waveguide grating and polarisation rotator/splitter. Electron. Lett. 2019, 55, 475-476. [CrossRef] 
25. Chen, S.; Fu, X.; Wang, J.; Shi, Y.; He, S.; Dai, D. Compact dense wavelength-division (de) multiplexer utilizing a bidirectional arrayed-waveguide grating integrated with a Mach-Zehnder interferometer. J. Light. Technol. 2015, 33, 2279-2285. [CrossRef]

26. Olivier, S.; Rattier, M.; Benisty, H.; Weisbuch, C.; Smith, C.; De La Rue, R.; Krauss, T.; Oesterle, U.; Houdré, R. Mini-stopbands of a one-dimensional system: The channel waveguide in a two-dimensional photonic crystal. Phys. Rev. B 2001, 63, 113311. [CrossRef]

27. Olivier, S.; Benisty, H.; Weisbuch, C.; Smith, C.J.; Krauss, T.F.; Houdré, R. Coupled-mode theory and propagation losses in photonic crystal waveguides. Opt. Exp. 2003, 11, 1490-1496. [CrossRef]

28. Cao, T.; Cryan, M.J.; Ivanov, P.S.; Ho, D.; Ren, B.; Craddock, I.J.; Rorison, J.M.; Railton, C.J. Modeling of chirped pulse propagation through a mini-stop band in a two-dimensional photonic crystal waveguide. J. Opt. Soc. Am. B 2007, 24, 1575-1583. [CrossRef]

29. Benisty, H.; Cambournac, C.; Van Laere, F.; Van Thourhout, D. Photonic-crystal demultiplexer with improved crosstalk by second-order cavity filtering. J. Light. Technol. 2010, 28, 1201-1208. [CrossRef]

30. Shahid, N.; Amin, M.; Naureen, S.; Swillo, M.; Anand, S. Junction-type photonic crystal waveguides for notch-and pass-band filtering. Opt. Exp. 2011, 19, 21074-21080. [CrossRef] [PubMed]

31. Ayre, M.; Cambournac, C.; Khayam, O.; Benisty, H.; Stomeo, T.; Krauss, T. Photonic crystal waveguides for coarse-selectivity devices. Photonics Nanostruct. 2008, 6, 19-25. [CrossRef]

32. Moore, S.; O'Faolain, L.; White, T.; Krauss, T. Photonic crystal laser with mode selective mirrors. Opt. Exp. 2008, 16, 1365-1370. [CrossRef]

33. Qiu, H.; Jiang, J.; Yu, P.; Yang, J.; Yu, H.; Jiang, X. Broad bandwidth and large fabrication tolerance polarization beam splitter based on multimode anti-symmetric Bragg sidewall gratings. Opt. Lett. 2017, 42, 3912-3915. [CrossRef]

34. Huang, Q.; Jie, K.; Liu, Q.; Huang, Y.; Wang, Y.; Xia, J. Ultra-compact, broadband tunable optical bandstop filters based on a multimode one-dimensional photonic crystal waveguide. Opt. Exp. 2016, 24, 20542-20553. [CrossRef]

35. Shi, W.; Yun, H.; Lin, C.; Greenberg, M.; Wang, X.; Wang, Y.; Fard, S.T.; Flueckiger, J.; Jaeger, N.A.; Chrostowski, L. Ultra-compact, flat-top demultiplexer using anti-reflection contra-directional couplers for CWDM networks on silicon. Opt. Exp. 2013, 21, 6733-6738. [CrossRef] [PubMed]

36. Chen, J.; Shi, Y. Flat-Top CWDM (De) multiplexers Based on Contra-directional Couplers with Subwavelength Gratings. IEEE Photon. Technol. Lett. 2019, 31, 2003-2006. [CrossRef]

37. Chen, L.; Doerr, C.R.; Chen, Y.-k. Polarization-diversified DWDM receiver on silicon free of polarization-dependent wavelength shift. In Proceedings of the Optical Fiber Communication Conference, Los Angeles, CA, USA, 4-8 March 2012; pp. 1-3.

38. Corzine, S.W.; Evans, P.; Fisher, M.; Gheorma, J.; Kato, M.; Dominic, V.; Samra, P.; Nilsson, A.; Rahn, J.; Lyubomirsky, I. Large-scale InP transmitter PICs for PM-DQPSK fiber transmission systems. IEEE Photon. Technol. Lett. 2010, 22, 1015-1017. [CrossRef]

39. Wang, X.; Wang, Y.; Flueckiger, J.; Bojko, R.; Liu, A.; Reid, A.; Pond, J.; Jaeger, N.A.; Chrostowski, L. Precise control of the coupling coefficient through destructive interference in silicon waveguide Bragg gratings. Opt. Lett. 2014, 39, 5519-5522. [CrossRef]

40. Jiang, J.; Qiu, H.; Wang, G.; Li, Y.; Dai, T.; Mu, D.; Yu, H.; Yang, J.; Jiang, X. Silicon lateral-apodized add-drop filter for on-chip optical interconnection. Appl. Opt. 2017, 56, 8425-8429. [CrossRef] [PubMed]

41. Cheng, R.; Chrostowski, L. Spectral Design of Silicon Integrated Bragg Gratings: A Tutorial. J. Light. Technol. 2020, 39, 712-729. [CrossRef]

42. Liu, Y.; Wang, S.; Wang, Y.; Liu, W.; Xie, H.; Yao, Y.; Song, Q.; Zhang, X.; Yu, Y.; Xu, K. Subwavelength polarization splitter-rotator with ultra-compact footprint. Opt. Lett. 2019, 44, 4495-4498. [CrossRef] 